\title{
Vacations Over the Years: A Cross-Lagged Panel Analysis of Tourism Experiences and Subjective Well-Being in the Netherlands
}

\section{Ondrej Mitas $^{1}$ (D) Maarten Kroesen ${ }^{2}$}

Published online: 7 December 2019

(C) The Author(s) 2019

\begin{abstract}
Tourism experiences, also called vacations, are known to boost subjective well-being, although it has been argued that the effects are primarily affective in nature and short-lived. We argue that this is a methodological artifact due to the brief duration-1 year or lessof almost all extant longitudinal studies of tourism experience effects. Based on broadenand-build and personal resource theories, we hypothesize that tourism experiences contribute to both affective and cognitive components of subjective well-being over a multi-year timespan. Using random intercept cross-lagged panel models, we tested these hypotheses in 8 years of panel data based on a representative sample of the population of the Netherlands. We found both between- and within-individual effects of vacation frequency on cognitive as well as affective well-being. More frequent vacationers experienced higher life satisfaction and lower negative affect, while the average participant also experienced slightly higher life satisfaction and positive affect following a year with higher vacation frequency. Increases in life satisfaction also predicted more frequent vacationing in a following year, consistent with an "upward spiral" pattern of improving well-being based on accumulation of positive experiences, as suggested by the broaden-and-build theory.
\end{abstract}

Keywords Vacations $\cdot$ Tourism $\cdot$ Experiences $\cdot$ Life satisfaction $\cdot$ Affect $\cdot$ Panel data Cross-lagged panel model

\section{Introduction}

Many people point to tourism experiences as containing the happiest moments of their lives. Tourism experiences, usually defined as spending at least one night away from one's usual home for leisure purposes (World Tourism Organization 1994) are characterized by novelty, leisure, and detachment from daily hassles (Mitas et al. 2012a). Thus, it is no surprise that the relationship between tourism experiences and happiness has become an issue

Ondrej Mitas

Mitas.O@buas.nl

1 Breda University of Applied Sciences, Mgr. Hopmansstraat 2, 4817JS Breda, The Netherlands

2 Delft University of Technology, Jaffalaan 5, 2628BX Delft, The Netherlands 
of substantial research interest. Since 2008, no less than five $\mathrm{PhD}$ projects have focused on this topic (Nawijn 2012; Mitas 2010; Hagger 2009; Filep 2009; de Bloom 2012). Consumer behavior scholars (Neal et al. 1999; Sirgy et al. 2011; Uysal et al. 2016), and psychologists (Kemp et al. 2008; Wirtz et al. 2003) have also explored the link between tourism experiences and happiness.

Most of these studies have adopted a subjective well-being definition of happiness, which posits happiness as being composed of affective and cognitive components. Research under the subjective well-being view suggests that the effects of tourism experiences on happiness are generally affective and short-lived (Mitas et al. 2017). As the title of one study puts it, tourism experiences are "lots of fun, quickly gone" (de Bloom et al. 2010). In the present study, we argue that this finding, though common, is an artifact of the limited data sets on which these studies are based. To uncover cognitive and longerterm effects of engaging in tourism experiences, it is necessary to follow individuals over a multi-year time span in which the effects of years with and without tourism experiences can be traced, including changes in income, which influence people's ability to travel (Dolnicar et al. 2008). We present such an analysis to show that tourism experiences do indeed have long-term effects on multiple happiness components.

\section{Literature Review}

Building on several pioneering studies from the 1980s and 90s (Lounsbury and Hoopes 1986), the past decade has seen a substantial body of research on tourism experiences and happiness. The link between tourism experiences and happiness has been studied from the perspective of tourists (Neal et al. 1999) as well as local residents in tourism areas (Nawijn and Mitas 2012). Existing studies have often used theoretical perspectives from positive psychology (Mitas et al. 2012b; Filep and Deery 2010), but also organizational psychology (Westman and Etzion 2001; Fritz and Sonnentag 2006), consumer psychology (Uysal et al. 2016; Sirgy et al. 2011), medicine (Gump and Matthews 2000; Strauss-Blasche et al. 2000), and public health (Eaker et al. 1992). The cited studies are merely examples of this growing stream of research, which has become too extensive to fully review here. Such reviews exist elsewhere (Mitas et al. 2017). Instead, we give here an update and criticism of this literature pointed at the lack of multi-year studies.

Most existing research on tourism experiences and happiness conceptualizes happiness as subjective well-being (Lyubomirsky et al. 2005). The subjective well-being perspective suggests that individuals are best-positioned to evaluate their own happiness. In other words, people are understood to be as happy as they say they are. Furthermore, happiness is believed to be composed of cognitive and affective components, which are often operationalized as life satisfaction and positive and negative emotions and moods, respectively. While a majority of the cited studies measure one or more of these components as an operationalization of happiness, not one, to our knowledge, measures them all. Many measure only moods (Strauss-Blasche et al. 2004a, b), emotions (Mitas et al. 2012a; Wirtz et al. 2003), or life satisfaction (Neal et al. 1999, 2007). Such single-variable approaches to measuring happiness are necessarily incomplete.

At least five studies of tourism experiences and happiness measure at least one cognitive and at least one affective dimension of happiness (Sirgy et al. 2011; Nawijn 2010, 2011a; Gilbert and Abdullah 2004; Chen and Li 2018). While relatively more complete than, for example, studies which measure only emotions or only life satisfaction, these studies have 
limitations of their own, mainly that their data cover only a single year of participants' lives. It is also worth noting that at least four studies assess happiness in general rather than one or more of its components (Nawijn et al. 2013a; Bimonte and Faralla 2016; Milman 1998; Nawijn and Peeters 2010).

The findings from existing research on tourism experiences and happiness form a relatively consistent pattern. Tourism experiences have a consistent positive effect on affect, boosting positive emotions or moods shortly before, during, and shortly after the experience itself, while negative emotions or moods tend to remain unchanged. More precisely, positive emotions or moods often follow a "peak model," in which they gradually rise in the days leading up to a tourism experience, are elevated during, and gradually decline after (Mitas et al. 2012a). This model holds over different time scales, for example within the tourism experience itself (Nawijn 2010; Nawijn et al. 2013b) and over the course of 1 year during which a tourism experience occurs (Nawijn et al. 2010). The rapid decline of emotions after a tourism experience raises the question, however, if a brief temporary boost in positive emotions is the only happiness benefit herein.

The broaden-and-build theory (Fredrickson 1998, 2001; Fredrickson et al. 2008; Garland et al. 2010) suggests that even brief experiences of positive emotion can have consequences for long-term happiness through accumulation of personal resources. In a nutshell, the theory posits that, during experiences of positive emotion, individuals consider a broader repertoire of possible thoughts and actions ('broadening'). Approaching the world in such a 'broadened' way makes it easier for individuals to build valuable personal resources, especially constructive relationships with other people ('building'). Furthermore, Fredrickson and colleagues posit that long-term cumulative building makes individuals more open to undertake potentially positive experiences. Thus, sufficiently frequent positive emotions eventually lead to 'upward spirals' of durable increases in happiness (Garland et al. 2010; Fredrickson and Joiner 2002; Kok and Fredrickson 2010; Stiglbauer et al. 2013). The upward spirals hypothesis would thus suggest that, as individuals build long-term happiness, they may also undertake tourism experiences more frequently, a hypothesis thus untested in tourism research. To determine if the long-term effects of broaden-and-build processes are evident in the context of tourism experiences, a multi-year analysis is needed, in which multiple dimensions of happiness during years with more and fewer (or no) tourism experiences are examined.

Effects of tourism experiences on cognitive components of happiness, usually life satisfaction, are much less consistent. Some studies show no link between tourism experiences and life satisfaction (Strauss-Blasche et al. 2000; Nawijn 2011b; Mitas 2010), while others show that life satisfaction increases after a tourism experience compared to before (Gilbert and Abdullah 2004; Hoopes and Lounsbury 1989; Lounsbury and Hoopes 1986; McCabe and Johnson 2013) or is at least related to levels of satisfaction with the experience in a between-participants analysis (Neal et al. 2007). The inconsistency across these studies is not surprising, as life satisfaction is believed to be relatively stable compared to emotions (Eid and Diener 2004), whereas each of the cited studies was either cross-sectional or featured multiple waves of data collection within a single year.

Theoretical explanations for a multi-year link between tourism experiences and life satisfaction, and happiness more generally, exist. The broaden-and-build theory alleges that brief experiences of positive emotions, which are salient during tourism experiences (Mitas et al. 2012b), build resources such as friendships and creativity, which often last several years or more and contribute to life satisfaction in turn (Fredrickson 2001). Along the same lines, theories about the conservation of personal resources, such as effort-recovery theory, allege that exhaustion due to work and daily hassles must be regularly offset by periods 
of recovery, such as tourism experiences, to maintain long-term well-being, including life satisfaction (de Bloom et al. 2010). In a sense, the broaden-and-build theory explains how tourism experiences may contribute to life satisfaction via positive experiences, whereas effort-recovery theory explains this effect via (fewer) negative experiences. Both theories suggest that the benefits of relatively short experiences, such as most tourism experiences, can maintain or grow an individual's life satisfaction over time. Thus, the true effect of tourism experiences on life satisfaction may only be evident across multiple years of data including variation in (often annual) habits. For a more robust analysis of the link between life satisfaction and tourism experiences, several years of data are needed, showing how life satisfaction evolves in relation to tourism experiences over a longer time span.

A notable minority of studies linking tourism experiences and happiness opt for a eudaimonic view of happiness, although these tend to be theoretical in approach (Smith and Puczkó 2008; Filep and Deery 2010). In the present study we choose to focus on the subjective well-being perspective on happiness, rather than eudaimonic happiness in particular, because it is the more widely used of the two perspectives in previous empirical research linking tourism and happiness. Thus, we aimed at comparing our findings to the more substantial of the two happiness research streams in the tourism literature.

In sum, the links between tourism experiences and happiness have been studied and findings consistently show a short-lived positive relationship, especially for the affective component of happiness. Two main shortcomings forestall robust conclusions about the link between tourism experiences and happiness, however. First, existing studies have looked only at happiness and tourism experiences at a single point in time, or development of these variables over a single year; and second, existing studies usually feature rather incomplete happiness metrics, focusing on either positive affect, life satisfaction, or a general index, rather than separately analyzing all of these as well as negative affect.

The broaden-and-build theory suggests that brief experiences of positive emotions lead to building of durable resources which in turn contribute to both affective and cognitive components of happiness over months and years. It is also suggested that this accumulation of happiness may motivate undertaking further enjoyable experiences, as tourism experiences tend to be, in an 'upward spiral' (Fredrickson and Joiner 2002). There is extensive empirical support for broaden-and-build processes (Fredrickson et al. 2008; Garland et al. 2010; Cohn et al. 2009). Furthermore, theories about conversation of personal resources posit a somewhat comparable process for regulating negativity arising from work and daily hassles (de Bloom et al. 2010). Thus, it is likely that tourism experiences contribute to both affective and cognitive components of happiness over a multi-year timespan. However, testing this hypothesis requires multiple years of tourism experience and happiness data. Research based on a single year of data does not show consistent durable happiness effects of tourism experiences, possibly because such benefits take several years to accrue, or because tourism experiences merely maintain a baseline level of happiness. In that case, a single tourism experience would not durably boost happiness, but if this is an annual habit, skipping it for a year would noticeably decrease happiness. Furthermore, whether tourism experiences maintain or gradually build happiness may depend on the frequency of tourism experiences. Untangling these effects requires a multi-year dataset which measures frequency of tourism experiences as well as cognitive, affective, and overall components of happiness annually.

To our knowledge, only one such study exists, and it supports the hypothesis discussed above, that tourism experiences contribute to happiness over the course of several years (Kroesen and Handy 2014). However, this study was limited by the use of a conventional cross-lagged panel model (CLPM) for analysis, which does not account for the fact that 
individual persons in the dataset have different baseline levels of happiness. Accounting for stable individual differences requires a random-intercept cross-lagged panel model (RI-CLPM) (Hamaker et al. 2015), which would lead to a more precise assessment of the effects of tourism experiences on happiness over the years. Furthermore, while Kroesen and Handy (2014) used 4 years of data, a dataset with a longer time span could support more robust conclusions. Finally, Kroesen and Handy measured affective and cognitive components of happiness with single-item measures, which arguably do not capture the complexity of happiness as completely as validated multi-item scales designed for this purpose.

In the present study we analyze the effects of tourism experience frequency (henceforth "vacation frequency" for brevity) on the affective and cognitive components of happiness, as measured by validated multi-item scales, over a 9-year period using a random-intercept cross-lagged panel model. Following the subjective well-being framework of happiness, we operationalize the cognitive component of happiness as life satisfaction and the affective component of happiness as positive affect and negative affect.

\subsection{Hypotheses}

Inspired by the broaden-and-build theory, which alleges that brief experiences of positive emotions translate to durable personal resources which build happiness over time, and the peak model of tourist emotions, which suggests that tourism experiences are usually more emotionally positive than day to day life, we test that:

H1 Vacation frequency in each year is positively related to life satisfaction in the following year, over a course of multiple years.

H2 Vacation frequency in each year is positively related to positive affect in the following year, over a course of multiple years.

H3 Vacation frequency in each year is negatively related to negative affect in the following year, over a course of multiple years.

While not the main target of this investigation, we believe it is also important to model the reverse effect, that is, the relationship between life satisfaction or affect in 1 year and vacation frequency the following year, to partition out and assess the possibility that a year with increased happiness is followed by a year with more tourism experiences. Such a link would support the 'upward spirals' hypothesis posited by several accounts of the broadenand-build theory.

\section{Methods}

\subsection{Data}

Data for the present analysis are drawn from the LISS panel (Longitudinal Internet Studies for the Social sciences), a panel of approximately 8000 individuals (more information on this panel can be found at http://www.lissdata.nl/). The panel is based on a true probability sample of households drawn from the population register by Statistics Netherlands. 
Households that could not otherwise participate are provided with a computer and Internet connection. Panel members complete online questionnaires every month and are paid for each completed questionnaire.

In this study, data from two regular surveys of the LISS panel are combined, namely the social integration and leisure survey, which includes data on people's leisure and tourism experiences, and the personality survey, which includes data on people's happiness. From 2008 onwards both of these surveys have been administrated annually (in February and May of each year respectively). The present analysis is based on those individuals who participated in all nine of the currently available waves, 1614 persons in total. Table 1 presents the sample distributions of the socio-demographic variables of the respondents in the first year of the panel (2008). Overall, these distributions fit well with the respective (Dutch) population distributions of these variables at that point in time.

Biases may be introduced because of the decision to base the analysis only on respondents who completed all waves. To assess this, the distributions of the sociodemographic variables of the selected sample $(n=1614)$ were compared with the distributions of all individuals who participated in at least one wave/year $(n=7904)$. This comparison showed that there were no large differences in the distributions of gender, income and education

Table 1 Sample distributions of socio-demographic characteristics

\begin{tabular}{|c|c|c|}
\hline Variable & Categories & $\%$ \\
\hline \multirow[t]{2}{*}{ Gender } & Male & 50 \\
\hline & Female & 50 \\
\hline \multirow[t]{5}{*}{ Age } & $15-34$ years & 12 \\
\hline & 35-44 years & 17 \\
\hline & $45-54$ years & 24 \\
\hline & $55-64$ years & 31 \\
\hline & 65 years and older & 17 \\
\hline \multirow[t]{6}{*}{ Level of education } & Primary school & 9 \\
\hline & Intermediate secondary education & 29 \\
\hline & Higher secondary education & 9 \\
\hline & Intermediate vocational education & 23 \\
\hline & Higher vocational education (college) & 23 \\
\hline & University & 6 \\
\hline \multirow[t]{6}{*}{ Occupational status } & Paid employment & 48 \\
\hline & Freelancer, or self-employed & 5 \\
\hline & Attends school or is studying & 4 \\
\hline & Takes care of the housekeeping & 12 \\
\hline & Pensioner & 20 \\
\hline & Other & 11 \\
\hline \multirow[t]{7}{*}{ Personal net income } & No income & 10 \\
\hline & EUR 500 or less & 7 \\
\hline & EUR 501 to EUR 1000 & 18 \\
\hline & EUR 1001 to EUR 1500 & 22 \\
\hline & EUR 1501 to EUR 2000 & 22 \\
\hline & EUR 2001 to EUR 2500 & 11 \\
\hline & More than EUR 2500 & 10 \\
\hline
\end{tabular}

$N=1614$ 
level. Yet, differences were found with respect to age and occupational status; in particular, older people and pensioners were overrepresented in the selected sample. The possible effects of these biases on the estimated coefficients were explored and are discussed in the "Results" section.

While the LISS panel is nationally representative for the Netherlands, the use of a wholly Dutch sample in the present study limits generalizability to individuals in other countries. Typical of Western Europeans, most Dutch citizens undertake tourism experiences regularly, often during school vacation periods in August and late February (Bargeman and van der Poel 2006). It is important to keep this cultural context in mind when interpreting the findings. North Americans, as a counterexample, are often structurally unable to undertake tourism experiences, or choose to work or to stay home through granted vacation days (Hilbrecht and Smale 2016). Connections between tourism experiences and happiness may differ greatly in such a cultural context, where undertaking tourism experiences is less of an established ritual.

\subsection{Measures}

The LISS social integration and leisure survey measures frequency of tourism experiences as the number of vacations of one night or more away from home, in the past 12 months, measured on an integer scale from 0 to 10 (with 10 indicating ' 10 or more'). While this quantity may not capture various qualitative aspects of tourism experiences, the benefit of using a simple measure is that it is easy to compare across persons and is unlikely to be strongly affected by (random or systematic) measurement errors.

Life satisfaction (hypothesis 1) is measured using the Satisfaction With Life Scale (SWLS) (Diener et al. 1985). Well-known in the happiness research literature, the SWLS is a 5-item scale designed to measure global cognitive judgments of one's life satisfaction, including statements such as "In most ways my life is close to my ideal." Participants indicated agreement with each item using a 7-point Likert-type scale. In the present study, the items are summed leading to a scale that (theoretically) ranges from 5 to 35 . The reliability and predictive validity of the SWLS has been shown in numerous studies (Pavot et al. 1991; Pavot and Diener 1993).

To operationalize positive and negative affect, the Positive Affect and Negative Affect Schedule (PANAS) scales developed by Watson et al. (1988) are used. These scales are intended to measure independent affective activation dimensions, i.e. the extent a person is in a state of high energy, full concentration, and pleasant engagement (positive affect) and the extent a person is in a state of subjective distress and unpleasant engagement (negative affect). Items relating to positive affect include, for example, enthusiastic, active, or alert, while for negative affect they include emotions like distressed, irritable or scared. Each item is rated on a 7-point scale ranging from 1 (not at all) to 7 (extremely). Hence, after summation, the scales (theoretically) range from 10 to 70. Similar to the SWL scale, the PANAS scales have been validated in many countries and samples (Crawford and Henry 2004).

Vacation frequency and the SWLS were included in all surveys (from 2008 onwards). However, the PANAS scales were not included in the years 2010, 2012 and 2015. Hence, for these outcomes only six waves of data were available. Thus, the time lags between the measurements also varied (between 1 and 2 years). The models were specified accordingly.

Table 2 presents, for each year, the descriptive statistics of vacation frequency and the three well-being scales as well as the cross-sectional zero-order correlations between them. 
Table 2 Descriptive statistics of holiday behaviour and the three well-being scales $(\mathrm{N}=1614)$

\begin{tabular}{|c|c|c|c|c|c|c|c|c|c|c|c|}
\hline \multirow[t]{2}{*}{ Wave no. } & \multicolumn{2}{|c|}{ \#Holidays } & \multicolumn{3}{|c|}{$\begin{array}{l}\text { SWLS } \\
\text { Range } \alpha=[0.88-0.89]\end{array}$} & \multicolumn{3}{|c|}{$\begin{array}{l}\text { NA } \\
\text { Range } \alpha=[0.91-0.93]\end{array}$} & \multicolumn{3}{|c|}{$\begin{array}{l}\text { PA } \\
\text { Range } \alpha=[0.85-0.88]\end{array}$} \\
\hline & Mean & SD & Mean & SD & $\mathrm{r}^{\mathrm{a}}$ & Mean & SD & $\mathrm{r}^{\mathrm{a}}$ & Mean & SD & $\mathrm{r}^{\mathrm{a}}$ \\
\hline 1 & 2.7 & 2.1 & 25.8 & 5.2 & $0.201 * *$ & 19.9 & 9.9 & $-0.081^{* *}$ & 46.7 & 9.2 & 0.023 \\
\hline 2 & 2.6 & 2.0 & 25.8 & 5.2 & $0.223 * *$ & 19.8 & 10.0 & $-0.073^{* *}$ & 45.5 & 9.5 & 0.016 \\
\hline 3 & 2.6 & 2.0 & 25.7 & 5.3 & $0.195^{* *}$ & & & & & & \\
\hline 4 & 2.5 & 2.0 & 25.8 & 5.3 & $0.241^{* *}$ & 19.9 & 10.3 & $-0.096^{* *}$ & 44.3 & 9.6 & 0.044 \\
\hline 5 & 2.4 & 2.0 & 25.7 & 5.4 & $0.224 * *$ & & & & & & \\
\hline 6 & 2.4 & 2.0 & 25.6 & 5.4 & $0.196^{* *}$ & 19.2 & 10.3 & $-0.065^{* *}$ & 44.6 & 10.0 & $0.051 *$ \\
\hline 7 & 2.4 & 2.0 & 25.5 & 5.5 & $0.254^{* *}$ & 19.6 & 10.4 & $-0.098^{* *}$ & 45.3 & 9.5 & $0.062 *$ \\
\hline 8 & 2.4 & 2.0 & 25.7 & 5.5 & $0.255^{* *}$ & & & & & & \\
\hline 9 & 2.4 & 2.0 & 25.5 & 5.5 & $0.265^{* *}$ & 20.1 & 10.6 & $-0.129 * *$ & 44.9 & 10.0 & 0.032 \\
\hline
\end{tabular}

*Correlation sign. at $p<0.05$

$* *$ Correlation sign. at $p<0.01$

apearson's correlation coefficient with the number of holidays in past year

Participants went, on average, on 2.7 vacations in the year. In the first few years this frequency decreased to 2.4 and then stabilized. With respect to the three well-being measures, there were no such obvious trends. Bivariate correlations indicate that life satisfaction is associated with vacation frequency, with correlations ranging from 0.195 to 0.265. The correlations with the affective components of happiness (negative affect and positive affect) are in the expected directions, but much weaker and, for positive affect, only significant (at the 5\% level) for two out of six waves.

\subsection{Statistical Model}

To test the bidirectional relationships between vacation frequency and happiness, the random intercept cross-lagged panel models (RI-CLPM) is used, a particular kind of structural equation model which has recently been proposed by Hamaker et al. (2015). The RI-CLPM is an extension of the traditional cross-lagged panel model (CLPM) (Finkel 1995), which was also used by Kroesen and Handy (2014) to study the effects of tourism experiences on happiness. The model is briefly introduced below. For a full description, see Hamaker et al. (2015).

Figure 1 presents the structure of the RI-CLPM for three waves of data. In the model $x_{t}$ and $y_{t}$ represent the observed variables (in the present case relating to vacation frequency and happiness concepts) which are assumed to influence each other over time. For each observed variable a corresponding latent variable is specified, $p_{t}$ and $q_{t}$ for $x_{t}$ and $y_{t}$, respectively. By fixing the paths linking the observed and latent variables to 1 and including means for each respective point in time $\left(\mu_{t}\right.$ and $\left.\pi_{t}\right)$, the variables $p_{t}$ and $q_{t}$ effectively represent the individuals' temporal deviations from the time-varying group means. This structure effectively centers the variables around the means, accounting for populationwide structural change in the variables of interest. For example, there may be a societal trend to increasingly engage in tourism experiences due to improving economic conditions.

Next, it is assumed that each occasion of $p_{t}$ and $q_{t}$ may influence future occasions of $p_{t}$ and $q_{t}$, which is captured by parameters $\alpha_{t}$ and $\delta_{t}$. In addition, in line with the main aim of 
Fig. 1 A 3-wave random intercept cross-lagged panel model (Hamaker et al. 2015)

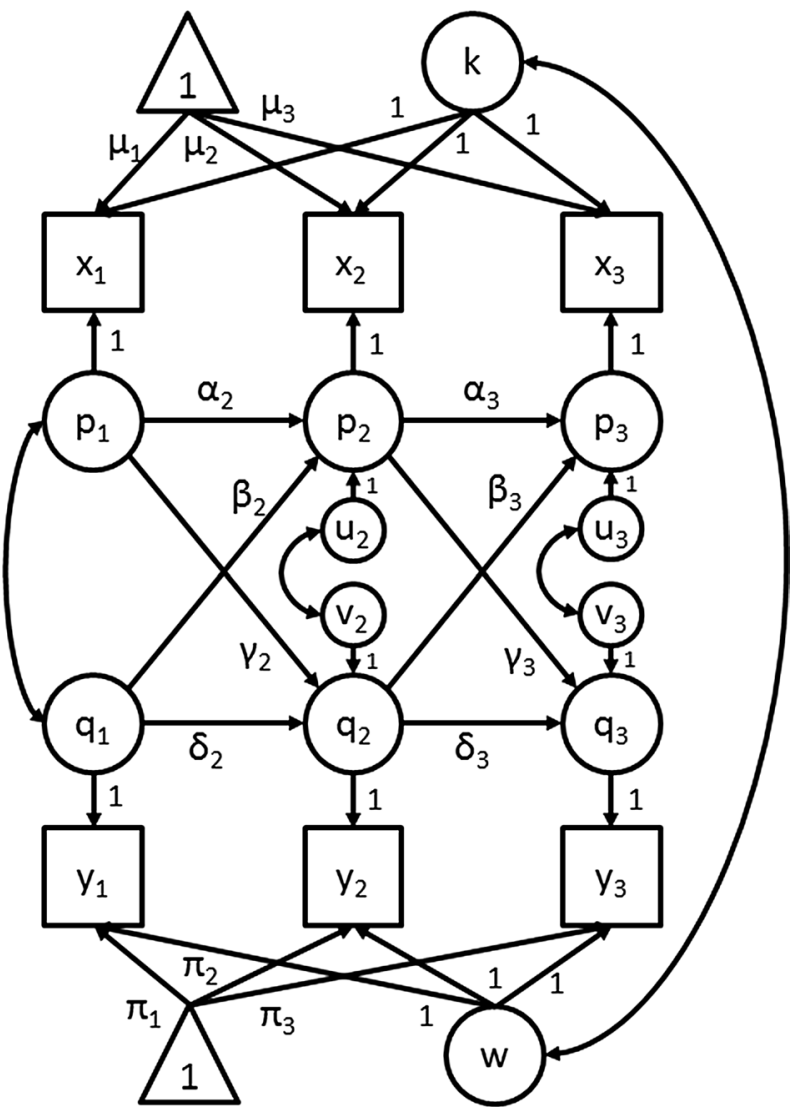

the RI-CLPM, $p_{t}$ and $q_{t}$ may influence each other over time, as captured by parameters $\beta_{t}$ and $\gamma_{t}$. The latter two 'cross-lagged' effects are of main interest for our research questions, as they indicate to what extent each variable in a given year influences the other in the following year, in both directions. Finally, the in models, $p_{t}$ and $q_{t}$ for the first point in time are allowed to be correlated capturing any initial overlap between the two variables due to previous causal influences in either direction. In a similar fashion, the error terms of $p_{t}$ and $q_{t}, u_{t}$ and $v_{t}$ respectively, are allowed to be correlated at each occasion after the first point in time.. These dynamic correlations capture possible synchronous effects between the two variables (i.e. $p_{t}$ and $q_{t}$ ).

An important drawback of the model as described so far is that, while the CLPM accounts for temporal stability (as captured by parameters $\alpha_{t}$ and $\delta_{t}$ ), it does not account for stable traitlike individual differences that endure over time. According to Hamaker et al. (2015), this is a problematic assumption, as psychological constructs are generally characterized by stable individual differences. Considering happiness, for example, there has been much research indicating it tends to be stable over a multi-year timespan in many individuals. Regarding behavioral outcomes (like annual vacation frequency), stable individual differences may arise due to the existence of habits and routines. To account for these stable individual differences Hamaker et al. (2015) propose the inclusion of two additional latent variables, $k$ and $w$ for $x$ and $y$ respectively, which can be regarded as random intercepts. The paths linking these 
variables to the observed variables are set to one, reflecting the notion that they have a constant (time-independent) 'trait-like' influence on the observed outcomes. Since the random intercepts capture variation between persons, stable 'between-person' variation is 'factored out'.

Accounting for stable between-participant differences has two important advantages. First, the stability/cross-lagged relations $\left(\alpha_{t}, \delta_{t}, \beta_{t}\right.$ and $\left.\gamma_{t}\right)$ now capture 'within-person' carry-over effects from one occasion to the next, i.e. the level at which the causal processes are actually assumed to operate, and second, all time-constant variables that may influence both variables $\left(x_{t}\right.$ and $\left.y_{t}\right)$ are controlled for. Finally, a correlation between $k$ and $w$ may be estimated. This correlation indicates the extent the variables of interest are correlated at the 'between-person' level, which is due to other factors than any causal effects between the two variables at the 'within-person' level.

\subsection{Model Specification}

While, in principle, it is possible to study the bidirectional influences between vacation frequency and the three well-being scales simultaneously, we decided to estimate separate models for each happiness variable, as with 6-9 occasions, the model was already quite complex (i.e., with many parameters).

To assess whether the RI-CLPM performed better than the CLPM in terms of model fit, both models were estimated for each happiness variable. In addition, to assess whether the lagged effects were constant over time, models were estimated with and without equality constraints on the cross-lagged effects. Especially for the hedonic components of happiness (NA and PA), for which the time lags between waves were not constant, it was expected that the effects of vacation frequency on affect would differ from wave to wave. The model variants ('RI-CLPM versus CLPM' and 'with and without constraint') yielded four combinations in total. Hence, for each happiness variable, four models were estimated (yielding a total of 12 models).

A benefit of the RI-CLPM is that time-constant confounding variables are controlled for through inclusion of the random intercepts $k$ and $w$. Yet, time-varying factors may still influence change in vacation frequency as well as change in happiness components $\left(x_{t}\right.$ and $\left.y_{t}\right)$. However, for each additionally included control variable, the model's complexity increases substantially. Therefore, only one time-varying control variable was included, the one believed most relevant in the explanation of vacation frequency and well-being, namely personal net income. The links between income and happiness as well as tourism experiences, though complex and variable by cultural context, are well-established empirically (Lyubomirsky et al. 2005). In the models, income is included for all waves (9 for SWLS and 6 for NA and PA) and assumed to influence both vacation frequency and the happiness variable in question. A random intercept for income, and correlations with the random intercept of vacation frequency and happiness are included as well.

All models were specified and estimated using maximum likelihood estimation in AMOS 23. 


\section{Findings}

Table 3 presents an overview of the model fit statistics of the 12 estimated models. In general, the CLPMs fit the data poorly according to the RMSEA, CFI and SRMR fit indices, while the RI-CLPMs fit the data very well according to these indices. Substantively, this means that there are indeed (enduring) stable individual differences in the variables considered in the analysis.

The differences in model fit between models with and without equality constraints on the cross-lagged parameters were much smaller. Here a series of Chi square differences tests (presented in the last three columns of Table 3) indicated that, with one exception, the decreases in model fit (as a result of imposing the constraints) were not statistically significant. Hence, except for the RI-CLPM for negative affect, the results indicated that the cross-lagged effects between vacation frequency and happiness variables were constant over time. We thus interpreted the relevant parameter estimates of the best fitting model for each happiness variable, namely, the random intercept model with constrained constant cross-lagged effects for life satisfaction and positive affect, and the random intercept model with unconstrained cross-lagged effects for negative affect.

Table 4 presents the standardized parameter estimates and the estimated correlations between the random intercepts of these three models. For life satisfaction, we found a positive reciprocal relationship with vacation frequency at the within-person level. Hence, on average, if a participant increased the number of her or his vacations in 1 year, (s)he experienced increased life satisfaction in the next year (0.023). The converse was also true: on average, when a participant was more satisfied with life in 1 year, (s)he increased his/her vacation frequency in the next (0.037). The effect of vacation frequency in 1 year on life satisfaction in the next year was slightly smaller than the converse. In addition, a moderate correlation was found between the random intercepts of SLWS and vacation frequency (0.310), indicating that these concepts were associated at the between-person level for reasons not related to the within-person longitudinal effects.

No significant effects in either direction were found for negative affect. Here too, however, we found a sizeable negative correlation at the between-person level $(-0.151)$. For positive affect, there was a significant link between vacation frequency in 1 year and positive affect the following year (0.030) at the within-person level, but not vice versa. Furthermore, there was no significant correlation between positive affect and vacation frequency at the between-person baseline level. In sum, participants who vacationed more frequently experienced, on average, less negative affect and as much positive affect as participants who vacationed less frequently. When participants increased their vacation frequency in a given year, they felt on average more positive affect and as much negative affect the following year.

Regarding income, the results indicate that income (at the within-individual level) positively influences both vacation frequency and satisfaction with life (and thus is indeed a relevant confounding within-participants variable). The effects on negative and positive affect, however, do not reach statistical significance. To assess whether the biases in the socio-demographic variables due to attrition affected the estimates, the final models (models 4, 7 and 12) were additionally estimated based on the full sample $(n=7904)$ using the Full Information Maximum Likelihood (FIML) estimator. This estimator imputes probable values for the missing data based on the model structure and has been shown to be least biased compared to other methods to handle missing data 


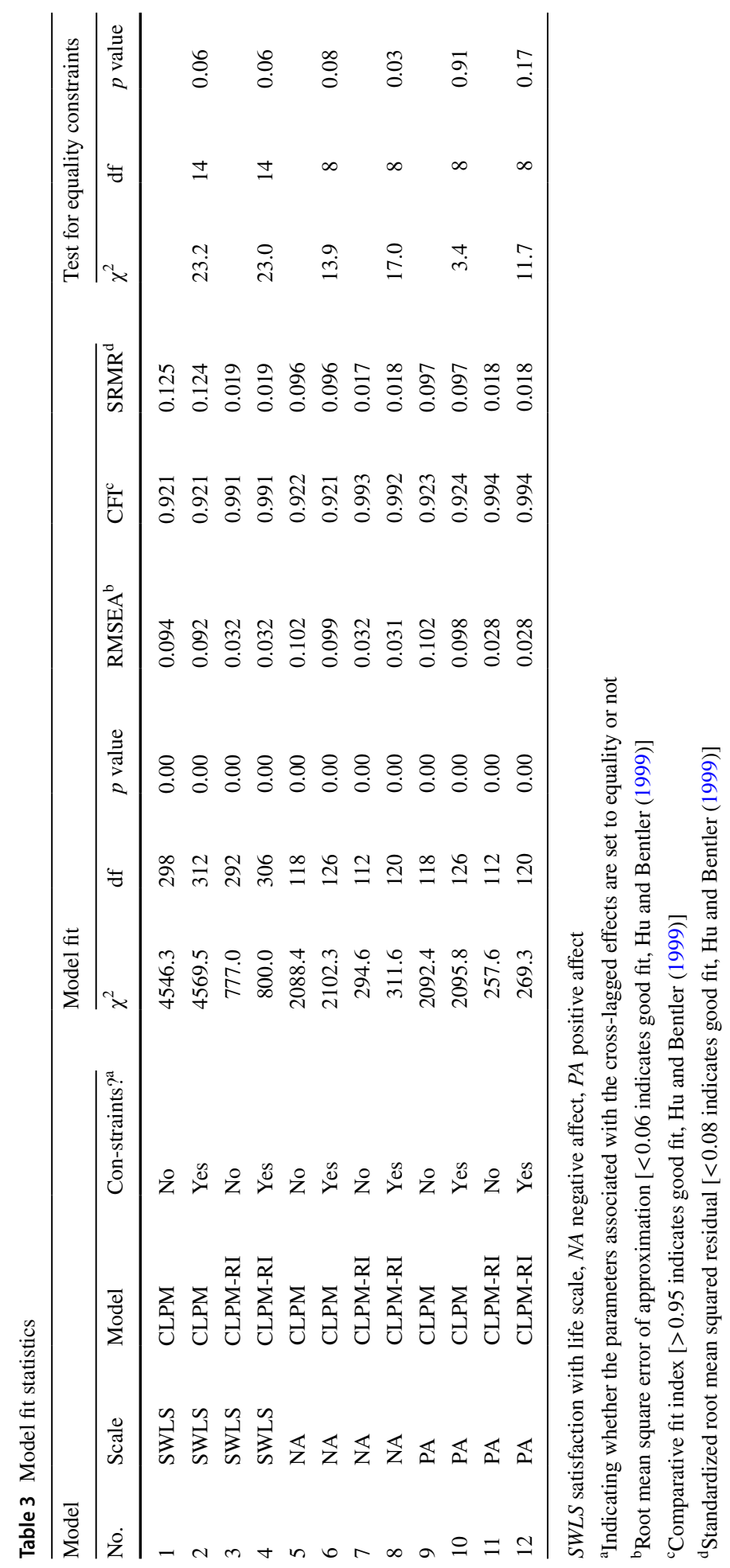


Table 4 Average standardized parameter estimates and correlations between random intercepts

\begin{tabular}{|c|c|c|c|c|c|c|}
\hline & \multicolumn{2}{|c|}{ SLWS (model 4) } & \multicolumn{2}{|c|}{ NA (model 7) } & \multicolumn{2}{|c|}{ PA (model 12) } \\
\hline & Est. & $p$ value & Est. & $p$ value & Est. & $p$ value \\
\hline \multicolumn{7}{|l|}{ Mean standardised estimate ${ }^{a}$} \\
\hline Holidays $\rightarrow$ SLWS/NA/PA & 0.023 & 0.02 & -0.003 & $>0.10$ & 0.030 & 0.03 \\
\hline SLWS/NA/PA $\rightarrow$ \#holidays & 0.037 & 0.00 & -0.012 & $>0.10$ & 0.019 & 0.15 \\
\hline Income $\rightarrow$ SLWS/NA/PA & 0.019 & 0.08 & 0.003 & $>0.10$ & 0.021 & $>0.10$ \\
\hline Income $\rightarrow$ \#holidays & 0.019 & 0.09 & 0.026 & 0.10 & 0.027 & 0.09 \\
\hline \multicolumn{7}{|c|}{ Correlations between random intercepts } \\
\hline \#Holidays $\leftrightarrow$ SLWS/NA/PA & 0.310 & 0.00 & -0.151 & 0.00 & 0.036 & $>0.10$ \\
\hline Income $\leftrightarrow$ SLWS/NA/PA & 0.095 & 0.00 & -0.141 & 0.00 & 0.029 & $>0.10$ \\
\hline Income $\leftrightarrow$ \#holidays & 0.210 & 0.00 & 0.207 & 0.00 & 0.207 & 0.00 \\
\hline
\end{tabular}

${ }^{a}$ We present the means of the standardized estimates across all waves. Note that, while the unstandardized estimates are equal across all waves (in models 4 and 12), the standardized estimates differ slightly from wave to wave, due to the time-varying variances of the variables

(Enders 2001). A comparison of the estimates of these models with those presented in Table 4 indicated that the deviations were generally small and did not lead to substantively different conclusions.

\section{Discussion and Conclusion}

Our findings show that vacation frequency is associated with all three global components of happiness within the subjective well-being framework, namely positive affect, negative affect, and life satisfaction, but at different levels, in a representative sample from the Netherlands. Vacation frequency was associated with higher life satisfaction and lower negative affect on a between-individual level. Furthermore, within the average individual, a year with more vacations was followed by a year with higher life satisfaction and higher positive affect. For life satisfaction only, this effect was bidirectional, so that years with higher life satisfaction were followed by years with higher vacation frequency as well. Thus, the temporal effects between life satisfaction and vacation frequency can be described as mutually reinforcing, along the lines of an 'upward spiral' posited by the broaden-and-build theory (Garland et al. 2010; Fredrickson and Joiner 2002). While the established within-individual effects between holiday frequency and life satisfaction (ranging from 0.023 to 0.037 ) are much smaller than the estimated between-individual correlation $(0.310)$, it should be remembered that the within-individual effects represent annual effects, which can potentially lead to large accumulated effects over multiple years. Below the findings are further discussed in relation to the growing literature on tourism experiences and happiness, as well as happiness research more generally.

Previously, existing research on the links between tourism experiences and happiness were based on datasets shorter than 24 months in duration, with the exception of Kroesen and Handy (2014). As we have argued in the literature, this was a significant gap in knowledge, as the habitual, often annual nature of tourism experiences may be crucial to their effect on happiness. Thus, only a multi-year dataset as in the present study could uncover how changes in annual tourism experience habits could affect happiness. Overall, 
the findings are in line with those of Kroesen and Handy (2014), indicating that vacation frequency has a positive bidirectional relationship with life satisfaction, the cognitive component of happiness. These findings contrast with the consensus from research using crosssectional or single-year datasets that the happiness benefits of tourism experiences are primarily affective (Mitas et al. 2017). It is therefore likely that, while tourism experiences contribute to both affective and cognitive components of happiness, the cognitive benefits emerge only over a multi-year course of development. Future research could explore the extent to which the habitual nature of, for example, summer vacations is responsible for this effect. Furthermore, future studies should compare the non-vacationers to vacationers in this sample to determine to what extent any tourism experience, or conversely skipping habitual tourism experiences, is driving the observed effects, as suggested by Nawijn et al. (2010).

Our findings diverge from those of Kroesen and Handy (2014) in the finding of a within-person link between vacation frequency and positive affect. This difference is most likely due to differences in measurement. Kroesen and Handy (2014) collapsed positive and negative affect into a single item, whereas we dealt with positive and negative affect separately, and used a validated multi-item scale for each. Studies linking positive affect to tourism experiences using validated multi-item scales have generally shown positive but short-lived effects under a "peak" model, wherein positive affect rises before a tourism experience, up to the middle of the experience itself, and declines afterward (de Bloom et al. 2010; Mitas et al. 2012a; Nawijn 2010). Our findings extend this literature to suggest that the peak model not only applies for time scales ranging from one tourism experience (Nawijn 2010) to 1 year (Nawijn et al. 2010), but also on a multi-year scale, in that years with more tourism experiences are followed by years with more positive affect. Based on this finding, we also hypothesize that a multi-year period in an individual's life with relatively more tourism experiences may form a relatively positive affective "peak" with respect to adjacent periods of their life.

Two theories of personal resources, the broaden-and-build theory (Fredrickson 1998) and effort-recovery theory (Meijman and Mulder 1998), were posited as possible explanations for the multi-year contribution of tourism experiences to happiness. These theories suggest that the temporary affective changes triggered by tourism experiences allow individuals to conserve and build their personal resources, contributing to life satisfaction in turn. Of the two theories, our findings of within-person links between tourism experiences and life satisfaction as well as positive affect, but not negative affect, are somewhat more consistent with broaden-and-build theory, which addresses positive emotions as a key mechanism. Conversely, effort-recovery theory suggests that well-being is supported by relief from the negative affective consequences of work and daily hassles. We found no link between vacation frequency and year-to-year changes in negative affect. It is possible, however, that such a link exists over smaller time scales, such as days or weeks. It is also possible that another dimension of tourism experiences, such as duration, is driving these effects. It is worth noting that most studies over smaller time scales show few or no changes in negative affect resulting from tourism experiences (Mitas et al. 2017). Future research using a measurement-burst design (Sliwinski 2008) could make the missing links between the different time scale of affective change resulting from tourism experiences.

We also found that increases in life satisfaction in 1 year predicted increases in vacation frequency the following year, consistent with the 'upward spirals' hypothesis of the broaden-and-build theory. This effect was larger than the influence of vacation frequency on life satisfaction the following year. The 'upward spirals' hypothesis posits that personal resources built during brief experiences of positive emotions, which 
are frequent during tourism experiences, make it easier to plan and undertake further positive experiences in the future (Fredrickson and Joiner 2002). For example, during a tourism experience, individuals may make friends in the host region or learn some aspects of local language and culture. More generally, traveling in unfamiliar surroundings may build confidence. These resources - friends, cultural awareness, confidencefacilitate future tourism experiences as well as life satisfaction more generally. Our data are consistent with this account, although future research could examine which resources are the most salient mechanism of the happiness-tourism effect. Existing research in tourism suggests the key resources could be primarily social (Mitas et al. 2012b; Yarnal 2004). Also, if a future dataset allowed such an analysis, the broadenand-build theory would posit that total time spent vacationing, not vacation frequency, would be the most potent predictor of happiness.

The within-person effects for life satisfaction and positive affect, however present, are not very large when compared with the correlations that exist at the between-person level for life satisfaction and negative affect. Thus, tourism experiences have a small but substantial influence on happiness and vice versa, while larger, stable interindividual differences indicate that people who vacation more frequently are generally happier. This finding was first proposed by Nawijn et al. (2010) in a comparison between vacationers and non-vacationers over a time scale of 1 year. Our analysis extends this pattern to a time scale of 8 years, and to the quantitative linear relationship between vacation frequency and happiness, rather than merely vacationing as a dichotomous variable, although more detailed tourism experience dimensions, such as duration and companions, were not measured. Furthermore, we have distinguished which happiness components - life satisfaction and negative affect-are at play in between-person differences.

It is important to note that these contributions are based on a representative sample from the Netherlands, where cultural norms favor vacationing frequently within established annual rhythms (Bargeman and van der Poel 2006). Much of Western Europe may follow the same norms, and could reasonably be expected to produce similar findings. Tourism experiences fulfil different roles in other cultures, however. Future research should examine how tourism experiences and happiness interact in a broader variety of cultures. Data from the Netherlands have featured prominently in research on this topic, as have data from the United States. Now, studies from East Asia are beginning to appear (Chen et al. 2013), raising hopes that knowledge about tourism experiences and happiness will become more universally applicable.

Between-person differences may be due to unassessed time-constant third variables. It is possible that differences in vacation frequency, negative affect, and life satisfaction overlap with individual differences which were not assessed here. These individual differences could be the drivers of both vacationing and happiness dimensions. Future research could reveal these individual differences, although serious health or financial problems are known to affect both tourism experiences (Hunter-Jones and Blackburn 2007) as well as happiness, and are thus likely candidates. Personality is another relevant interindividual variable to examine, as it is known to explain a substantial proportion of interindividual variation in happiness (Frew and Shaw 1999) as well as driving both choices and experiences of vacations (Lin et al. 2014). Personality dimensions such as extraversion and emotional stability have been linked with vacation frequency and happiness in past research (Kroesen and Handy 2014). 


\subsection{Limitations and Future Research Directions}

The most relevant limitation in the present study is the lack of a measure of tourism experience duration. We used the number of times a person engaged in a tourism experience each year, which we refer to as vacation frequency, as an independent variable. Each tourism experience, however, could have been between one night and one month or even longer in duration. It is hasty to assume that such potential extremes in tourism experience duration would have congruent effects on happiness, although previous studies of tourism and happiness accounting for duration reported no significant effects (Mitas et al. 2017). Many other dimensions of tourism experiences, such as choice of destination or who one travels with, may also affect happiness.

A second important limitation of the data set used is the application of the PANAS as an emotion scale. The PANAS lacks low-arousal positive emotions, and is thus particularly short-handed in contexts such as leisure or tourism, wherein relaxation and contentment are important goals (Mitas et al. 2012a). Future panels would be advised to replace or supplement the PANAS with a scale that more fully covers the affect circumplex, such as the SPANE (Diener et al. 2010), mDES (Cohn et al. 2009), or CES (Richins 1997). More generally, in addition to focusing on subjective well-being scales, it would also be relevant to study effects on eudaimonic well-being scales, which include indicators such as social relationships, meaning, self-esteem and self-actualization. As holidays are typically enjoyed together with family and/or friends, effects on these dimensions may be expected, and have been discussed in previous research (Filep and Deery 2010; Coghlan 2015).

Finally, several relevant reflections related to the modelling approach may also be identified. Firstly, while the subjective wellbeing scales used in this study were based on multiple items, the scales were not modelled as 'true' latent variables, as this would have added another layer of complexity. This means that measurement errors in the subjective constructs are not accounted for in the estimated structural relationships. It should be noted, however, that random measurement errors have a downwards effect on estimated coefficients, so the reported effects are underestimated rather than overestimated. A second reflection and related avenue for future research relates to potential accumulation effects of vacation frequency on subjective well-being. To some extent, such effects are captured by the adopted modelling approach, since the estimated coefficients represent annual effects. Yet, to more adequately capture accumulation effects, a different type of modelling framework would be necessary. A latent growth model could potentially be used for this purpose. Finally, the model we used factors out all time-constant variables including socio-demographics such as gender and age. Hence, the estimated within-individual effects (between holiday frequency and the happiness measures) are not affected by such variables, but the influences of these variables also cannot be explored within these models. One way to achieve this would be separately estimating models for different groups (e.g. men and women, different age groups, etc.) to assess whether effects are moderated by socio-demographic characteristics.

\subsection{Conclusion}

Using an 8-year dataset of annual surveys, we found that a representative sample of the Dutch population enjoys substantial happiness benefits from tourism experiences. More frequent vacationers experienced higher life satisfaction and lower negative affect, while 
the average participant also experienced slightly higher life satisfaction and positive affect following a year with higher vacation frequency. There was also a converse effect of life satisfaction increases predicting more frequent vacationing in a following year. These effects were found over and above the influence of changes in income. Overall, the findings suggest that relatively frequent tourism experiences make Dutch people happier, and increases in happiness lead to increased vacation frequency.

These findings suggest that laws related to vacation time and flexibility could be examined when happiness is a major public policy goal. Currently vacation and leave laws are the subject of vigorous debate in several countries. The present findings may contribute useful information to this debate, although the sizes of the (within-individual) effects are rather small and would not strongly support policies to increase holiday frequency. Finally, we have recommended several remaining questions for future research that also need to be addressed to definitively formulate policy advice. Namely, while we controlled for changes in income, the substantial between-individual effects observed should also be explained against the background of relevant control variables such as personality. Furthermore, besides income, health is a relevant source of within-person change to account for in future studies. Finally, future panel studies should be developed with the best available measures of both happiness and tourism behavior variables. In particular, measuring tourism experience duration as well as frequency would allow deeper insight in how individuals should plan their vacation travel time for optimum happiness.

Acknowledgements This research was co-financed by Regieorgaan SIA, a division of the Netherlands Organization for Scientific Research. We thank them for their support.

Open Access This article is distributed under the terms of the Creative Commons Attribution 4.0 International License (http://creativecommons.org/licenses/by/4.0/), which permits unrestricted use, distribution, and reproduction in any medium, provided you give appropriate credit to the original author(s) and the source, provide a link to the Creative Commons license, and indicate if changes were made.

\section{References}

Bargeman, B., \& van der Poel, H. J. T. M. (2006). The role of routines in the vacation decision-making process of Dutch vacationers. Tourism Management, 27(4), 707-720.

Bimonte, S., \& Faralla, V. (2016). Does residents' perceived life satisfaction vary with tourist season? A two-step survey in a Mediterranean destination. Tourism Management, 55, 199-208.

Chen, Y., Lehto, X. Y., \& Cai, L. (2013). Vacation and well-being: A study of Chinese tourists. Annals of Tourism Research, 42, 284-310.

Chen, Y., \& Li, X. R. (2018). Does a happy destination bring you happiness? Evidence from Swiss inbound tourism. Tourism Management, 65, 256-266.

Coghlan, A. (2015). Tourism and health: Using positive psychology principles to maximise participants' wellbeing outcomes-A design concept for charity challenge tourism. Journal of Sustainable Tourism, 23(3), 382-400.

Cohn, M. A., Fredrickson, B. L., Brown, S. L., Mikels, J. A., \& Conway, A. M. (2009). Happiness unpacked: Positive emotions increase life satisfaction by building resilience. Emotion, 9(3), 361.

Crawford, J. R., \& Henry, J. D. (2004). The positive and negative affect schedule (PANAS): Construct validity, measurement properties and normativedata in a large non-clinical sample. British Journal of Clinical Psychology, 43(3), 245-265.

de Bloom, J. (2012). How do vacations affect workers' health and well-being? Vacation (after-) effects and the role of vacation activities and experiences. Doctoral Dissertation, Radboud University Nijmegen, Oisterwijk. 
de Bloom, J., Geurts, S. A., Taris, T. W., Sonnentag, S., de Weerth, C., \& Kompier, M. A. (2010). Effects of vacation from work on health and well-being: Lots of fun, quickly gone. Work \& Stress, 24(2), $196-216$.

Diener, E., Emmons, R. A., Larsen, R. J., \& Griffin, S. (1985). The satisfaction with life scale. Journal of Personality Assessment, 49(1), 71-75.

Diener, E., Wirtz, D., Tov, W., Kim-Prieto, C., Choi, D.-W., Oishi, S., et al. (2010). New well-being measures: Short scales to assess flourishing and positive and negative feelings. Social Indicators Research, 97(2), 143-156.

Dolnicar, S., Crouch, G. I., Devinney, T., Huybers, T., Louviere, J. J., \& Oppewal, H. J. T. M. (2008). Tourism and discretionary income allocation. Heterogeneity among households. Tourism Management, 29(1), 44-52.

Eaker, E. D., Pinsky, J., \& Castelli, W. P. (1992). Myocardial infarction and coronary death among women: Psychosocial predictors from a 20-year follow-up of women in the Framingham Study. American Journal of Epidemiology, 135(8), 854-864.

Eid, M., \& Diener, E. (2004). Global judgments of subjective well-being: Situational variability and longterm stability. Social Indicators Research, 65(3), 245-277.

Enders, C. K. (2001). The performance of the full information maximum likelihood estimator in multiple regression models with missing data. Educational and Psychological Measurement, 61(5), 713-740.

Filep, S. (2009). Tourists' happiness through the lens of positive psychology. James Cook University.

Filep, S., \& Deery, M. (2010). Towards a picture of tourists' happiness. Tourism Analysis, 15(4), 399-410.

Finkel, S. E. (1995). Causal analysis with panel data (No. 105). Sage: London:

Fredrickson, B. L. (1998). What good are positive emotions? Review of General Psychology, 2(3), 300.

Fredrickson, B. L. (2001). The role of positive emotions in positive psychology: The broaden-and-build theory of positive emotions. American Psychologist, 56(3), 218.

Fredrickson, B. L., Cohn, M. A., Coffey, K. A., Pek, J., \& Finkel, S. M. (2008). Open hearts build lives: Positive emotions, induced through loving-kindness meditation, build consequential personal resources. Journal of Personality and Social Psychology, 95(5), 1045.

Fredrickson, B. L., \& Joiner, T. (2002). Positive emotions trigger upward spirals toward emotional wellbeing. Psychological Science, 13(2), 172-175.

Frew, E. A., \& Shaw, R. N. J. T. M. (1999). The relationship between personality, gender, and tourism behavior. Tourism Management, 20(2), 193-202.

Fritz, C., \& Sonnentag, S. (2006). Recovery, well-being, and performance-related outcomes: The role of workload and vacation experiences. Journal of Applied Psychology, 91(4), 936.

Garland, E. L., Fredrickson, B., Kring, A. M., Johnson, D. P., Meyer, P. S., \& Penn, D. L. (2010). Upward spirals of positive emotions counter downward spirals of negativity: Insights from the broaden-andbuild theory and affective neuroscience on the treatment of emotion dysfunctions and deficits in psychopathology. Clinical Psychology Review, 30(7), 849-864.

Gilbert, D., \& Abdullah, J. (2004). Holidaytaking and the sense of well-being. Annals of Tourism Research, 31(1), 103-121.

Gump, B. B., \& Matthews, K. A. (2000). Are vacations good for your health? The 9-year mortality experience after the multiple risk factor intervention trial. Psychosomatic Medicine, 62(5), 608-612.

Hagger, J. C. (2009). The impact of tourism experiences on post retirement life satisfaction. Doctoral Dissertation, University of South Australia.,

Hamaker, E. L., Kuiper, R. M., \& Grasman, R. P. (2015). A critique of the cross-lagged panel model. Psychological Methods, 20(1), 102.

Hilbrecht, M., \& Smale, B. (2016). The contribution of paid vacation time to wellbeing among employed Canadians. Leisure/Loisir, 40(1), 31-54.

Hoopes, L. L., \& Lounsbury, J. W. (1989). An investigation of life satisfaction following a vacation: A domain-specific approach. Journal of Community Psychology, 17(2), 129-140.

Hu, L. T., \& Bentler, P. M. (1999). Cutoff criteria for fit indexes in covariance structure analysis: Conventional criteria versus new alternatives. Structural Equation Modeling: A Multidisciplinary Journal, $6(1), 1-55$.

Hunter-Jones, P., \& Blackburn, A. (2007). Understanding the relationship between holiday taking and selfassessed health: An exploratory study of senior tourism. International Journal of Consumer Studies, 31(5), 509-516.

Kemp, S., Burt, C. D., \& Furneaux, L. (2008). A test of the peak-end rule with extended autobiographical events. Memory \& Cognition, 36(1), 132-138.

Kok, B. E., \& Fredrickson, B. L. (2010). Upward spirals of the heart: Autonomic flexibility, as indexed by vagal tone, reciprocally and prospectively predicts positive emotions and social connectedness. Biological Psychology, 85(3), 432-436. 
Kroesen, M., \& Handy, S. (2014). The influence of holiday-taking on affect and contentment. Annals of Tourism Research, 45, 89-101.

Lin, Y., Kerstetter, D., Nawijn, J., \& Mitas, O. (2014). Changes in emotions and their interactions with personality in a vacation context. Tourism Management, 40, 416-424.

Lounsbury, J. W., \& Hoopes, L. L. (1986). A vacation from work: Changes in work and nonwork outcomes. Journal of Applied Psychology, 71(3), 392.

Lyubomirsky, S., King, L., \& Diener, E. (2005). The benefits of frequent positive affect: Does happiness lead to success?. Washington, DC: American Psychological Association.

McCabe, S., \& Johnson, S. (2013). The happiness factor in tourism: Subjective well-being and social tourism. Annals of Tourism Research, 41, 42-65.

Meijman, T. F., \& Mulder, G. (1998). Psychological aspects of workload. In P. J. D. Drenth, H. Thierry, \& C. J. de Wolff (Eds.), Handbook of work and organizational psychology (2nd ed., Vol. 2, pp. 5-33). Hove, UK: Psychology Press/Erlbaum.

Milman, A. (1998). The impact of tourism and travel experience on senior travelers' psychological wellbeing. Journal of Travel Research, 37(2), 166-170.

Mitas, O. (2010). Positive emotions in mature adults' leisure travel experiences. Doctoral Dissertation, The Pennsylvania State University,

Mitas, O., Nawijn, J., \& Jongsma, B. (2017). Between tourists: Tourism and happiness. In M. K. Smith \& L. Puczko (Eds.), The Routledge handbook of health tourism (pp. 47-64). London: Routledge.

Mitas, O., Yarnal, C., Adams, R., \& Ram, N. (2012a). Taking a "peak" at leisure travelers' positive emotions. Leisure Sciences, 34(2), 115-135.

Mitas, O., Yarnal, C., \& Chick, G. (2012b). Jokes build community: Mature tourists' positive emotions. Annals of Tourism Research, 39(4), 1884-1905.

Nawijn, J. (2010). The holiday happiness curve: A preliminary investigation into mood during a holiday abroad. International Journal of Tourism Research, 12(3), 281-290.

Nawijn, J. (2011a). Determinants of daily happiness on vacation. Journal of Travel Research, 50(5), $559-566$

Nawijn, J. (2011b). Happiness through vacationing: Just a temporary boost or long-term benefits? Journal of Happiness Studies, 12(4), 651-665.

Nawijn, J. (2012). Leisure travel and happiness: An empirical study into the effect of holiday trips on individuals' subjective wellbeing. Doctoral Dissertation, NRIT Media, Nieuwegein,

Nawijn, J., De Bloom, J., \& Geurts, S. (2013a). Pre-vacation time: Blessing or burden? Leisure Sciences, 35(1), 33-44.

Nawijn, J., Marchand, M. A., Veenhoven, R., \& Vingerhoets, A. J. (2010). Vacationers happier, but most not happier after a holiday. Applied Research in Quality of Life, 5(1), 35-47.

Nawijn, J., \& Mitas, O. (2012). Resident attitudes to tourism and their effect on subjective well-being: The case of Palma de Mallorca. Journal of Travel Research, 51(5), 531-541.

Nawijn, J., Mitas, O., Lin, Y., \& Kerstetter, D. (2013b). How do we feel on vacation? A closer look at how emotions change over the course of a trip. Journal of Travel Research, 52(2), 265-274.

Nawijn, J., \& Peeters, P. M. (2010). Travelling 'green': Is tourists' happiness at stake? Current Issues in Tourism, 13(4), 381-392.

Neal, J. D., Sirgy, M. J., \& Uysal, M. (1999). The role of satisfaction with leisure travel/tourism services and experience in satisfaction with leisure life and overall life. Journal of Business Research, 44(3), 153-163.

Neal, J. D., Uysal, M., \& Sirgy, M. J. (2007). The effect of tourism services on travelers' quality of life. Journal of Travel Research, 46(2), 154-163.

Pavot, W., \& Diener, E. (1993). The affective and cognitive context of self-reported measures of subjective well-being. Social Indicators Research, 28(1), 1-20.

Pavot, W., Diener, E. D., Colvin, C. R., \& Sandvik, E. (1991). Further validation of the satisfaction with life scale: Evidence for the cross-methodconvergence of well-being measures. Journal of Personality Assessment, 57(1), 149-161.

Richins, M. L. (1997). Measuring emotions in the consumption experience. Journal of Consumer Research, 24(2), 127-146.

Sirgy, M. J., Kruger, P. S., Lee, D.-J., \& Yu, G. B. (2011). How does a travel trip affect tourists' life satisfaction? Journal of Travel Research, 50(3), 261-275.

Sliwinski, M. J. (2008). Measurement-burst designs for social health research. Social and Personality Psychology Compass, 2(1), 245-261.

Smith, M., \& Puczkó, L. (2008). Health and wellness tourism. London: Routledge. 
Stiglbauer, B., Gnambs, T., Gamsjäger, M., \& Batinic, B. (2013). The upward spiral of adolescents' positive school experiences and happiness: Investigating reciprocal effects over time. Journal of School Psychology, 51(2), 231-242.

Strauss-Blasche, G., Ekmekcioglu, C., \& Marktl, W. (2000). Does vacation enable recuperation? Changes in well-being associated with time away from work. Occupational Medicine, 50(3), $167-172$.

Strauss-Blasche, G., Muhry, F., Lehofer, M., Moser, M., \& Marktl, W. (2004a). Time course of wellbeing after a 3 -week resort-based respite from occupational and domestic demands: Carry-over, contrast and situation effects. Journal of Leisure Research, 36(3), 293.

Strauss-Blasche, G., Riedmann, B., Schobersberger, W., Ekmekcioglu, C., Riedmann, G., Waanders, R., et al. (2004b). Vacation at moderate and low altitude improves perceived health in individuals with metabolic syndrome. Journal of Travel Medicine, 11(5), 300-306.

Uysal, M., Sirgy, M. J., Woo, E., \& Kim, H. L. (2016). Quality of life (QOL) and well-being research in tourism. Tourism Management, 53, 244-261.

Watson, D., Clark, L. A., \& Tellegen, A. (1988). Development and validation of brief measures of positive and negative affect: The PANAS scales. Journalof Personality and Social Psychology, 54(6), 1063.

Westman, M., \& Etzion, D. (2001). The impact of vacation and job stress on burnout and absenteeism. Psychology \& Health, 16(5), 595-606.

Wirtz, D., Kruger, J., Scollon, C. N., \& Diener, E. (2003). What to do on spring break? The role of predicted, on-line, and remembered experience in future choice. Psychological Science, 14(5), 520-524.

World Tourism Organization. (1994). Recommendations on tourism statistics. Madrid: UNWTO Publications.

Yarnal, C. M. (2004). Missing the boat? A playfully serious look at a group cruise tour experience. Leisure Sciences, 26(4), 349-372.

Publisher's Note Springer Nature remains neutral with regard to jurisdictional claims in published maps and institutional affiliations. 